\title{
Dinosaurian and mammalian predators compared
}

\author{
Blaire Van Valkenburgh and Ralph E. Molnar
}

\begin{abstract}
Theropod dinosaurs were, and mammalian carnivores are, the top predators within their respective communities. Beyond that, they seem distinct, differing markedly in body form and ancestry. Nevertheless, some of the same processes that shape mammalian predators and their communities likely were important to dinosaurian predators as well. To explore this, we compared the predatory adaptations of theropod dinosaurs and mammalian carnivores, focusing primarily on aspects of their feeding morphology (skulls, jaws, and teeth). We also examined suites of sympatric species (i.e., ecological guilds) of predatory theropods and mammals, emphasizing species richness and the distribution of body sizes within guilds. The morphological comparisons indicate reduced trophic diversity among theropods relative to carnivorans, as most or all theropods with teeth appear to have been hypercarnivorous. There are no clear analogs of felids, canids, and hyaenids among theropods. Interestingly, theropods parallel canids more so than felids in cranial proportions, and all theropods appear to have had weaker jaws than carnivorans. Given the apparent trophic similarity of theropods and their large body sizes, it was surprising to find that species richness of theropod guilds was as great as or exceeded that observed among mammalian carnivore guilds. Separation by body size appears to be slightly greater among sympatric theropods than carnivorans, but the magnitude of size difference between species is not constant in either group. We suggest that, as in modern carnivoran guilds, smaller theropod species might have adapted to the threats posed by much larger species (e.g., tyrannosaurs) by hunting in groups, feeding rapidly, and avoiding encounters whenever possible. This would have favored improved hunting skills and associated adaptations such as agility, speed, intelligence, and increased sensory awareness.
\end{abstract}

Blaire Van Valkenburgh. Department of Organismic Biology, Ecology, and Evolution, University of California, Los Angeles, California 90095-1606. E-mail: bvanval@ucla.edu

Ralph E. Molnar. Museum of Northern Arizona, 3101 North Fort Valley Road, Flagstaff, Arizona 86001

Accepted: 4 June 2002

\section{Introduction}

Tyrannosaurus rex and the lion, Panthera leo, would seem to have little in common other than both being the largest carnivores in their respective ecosystems. Among their many differences, T. rex was a five-ton biped with reduced forelimbs and multiple serrated teeth; the other, a 100-kg quadruped with muscular, clawed forelimbs and teeth specialized for distinct functions, such as killing or slicing. Nevertheless, there is reason to believe that some of the same processes that shape mammalian predators and their communities were important to dinosaurian predators as well. Interspecific competition, for example, appears to play a significant role in determining the abundance and distribution of many large extant carnivores. For instance, by choosing to hunt at a different place or time, coyotes avoid wolves, cheetahs avoid lions, and leopards avoid tigers (Van Valkenburgh 2001). Associated with these behavioral differences are morphological differences that can be ex- plained as adaptations to minimize competition. Thus sympatric large carnivores usually differ in body size, dental morphology, or skeletal anatomy (see Eaton 1979; Van Valkenburgh 1985, 1988; Dayan et al. 1990, 1992). It might be expected that sympatric theropods diverged in a similar fashion if they faced comparable pressures from interspecific competition.

In this paper, we first review the relevant literature on mammalian carnivores to establish the background against which theropods will be viewed. We then compare some of the predatory adaptations of theropod dinosaurs and mammalian carnivores, focusing primarily on aspects of their feeding morphology (skulls, jaws, and teeth). This is followed by an examination of suites of sympatric species (i.e., ecological guilds) of predatory theropods and mammals, emphasizing species richness and the distribution of body sizes within guilds. The results presented here are not meant to be conclusive, as they are based on a limited sam- 
ple of mammals and theropods. Moreover, the gulf between carnivoran morphology and theropod morphology is large and this makes quantitative comparisons difficult. For example, theropods differ from carnivorans in limb stance (biped vs. quadruped), masticatory musculature, tooth replacement, and skull construction. Nevertheless, similar biomechanical and ecological constraints are expected to have been important to both kinds of predators. This paper is intended as no more than a preliminary exploration of trophic divergence among coexisting theropods, and it is our hope that it will inspire further, more-detailed studies.

\section{The Guild of Large, Predatory Mammals}

The ecological concept of guild was first defined by Root (1967: p. 335) as "a group of species that exploit the same class of environmental resources in a similar way." As such, species within a guild are expected to compete more intensely with each other than with those outside the guild. In theory, guilds are not limited by taxonomic boundaries; an extant predator guild could include reptiles, birds, and mammals, for example (see Jaksic et al. 1981). However, in practice, they often are so limited for various reasons, such as to maximize the potential role of competition or to facilitate the study (for review of the guild concept, see Simberloff and Dayan 1991).

Large, predatory mammals form a guild in which competition is expected to be relatively intense. Their shared food resources, prey, are often difficult and dangerous to kill, and consequently carcass theft (kleptoparasitism) is a worthwhile alternative to hunting. Carcass theft involves confrontation between individuals, which can be dangerous given that the participants are armed with teeth and jaws, and in some cases, claws, designed to kill. Moreover, given the species' predatory abilities, interspecific competition can be manifest as intraguild predation (Polis and Holt 1992). If competition among carnivores is as intense as predicted, then adaptations to minimize dangerous encounters and escape predation are expected in less dominant members of the guild.

Two recent reviews of the published litera- ture on interspecific interactions among extant large carnivores found ample evidence of carcass theft, intraguild predation, and interspecific avoidance in tropical and temperate ecosystems (Palomares and Caro 1999; Van Valkenburgh 2001). Four key points are summarized here. First, most interspecific interactions between predators occur as contests for the possession of a kill and these contests can be frequent. For example, in areas of high spotted hyena density, African wild dogs lost $60-86 \%$ of their kills to hyenas (Kruuk 1972; Fanshawe and Fitzgibbon 1993). As is true of carcass theft, the motivation for intraguild predation appears to be hunger in many instances. However, equally or more often, the victim is not eaten and the likely motivation is to remove a competitor who might also prey on young. Second, body size is the usual determinant of rank within the guild; larger species tend to dominate smaller ones (e.g., lion over hyena in Africa or wolf over coyote in North America). Third, the body size rule can be overturned by the smaller species acting as a group (e.g., hyenas vs. lions; African wild dogs vs. hyenas). Fourth, intraguild predation and kleptoparasitism occur in both forested and open environments. Although these types of interaction have been observed less frequently in forested environments, the behavior of some species strongly suggests that they have had a significant impact. For example, leopards avoid areas where tigers are common (Seidensticker 1976; Seidensticker et al. 1990), and do not cache their kills in trees where tigers and dholes are absent (Muckenhirn and Eisenberg 1973).

Previous work on morphological divergence among sympatric large carnivores substantiates the importance of interspecific competition over evolutionary timescales. In a series of papers, Van Valkenburgh (1985, 1988, 1991, 1994) explored morphological separation among large carnivores in past and present communities. Comparisons of dental and inferred dietary differences among sympatric predators from extinct and living communities revealed repeated patterns of divergence within guilds into meat specialists (e.g., felids, extinct nimravids), bone crackers (e.g., hyaenids, borophagine canids), and omnivores (e.g., 
coyotes, early amphicyonids). Within dietary types, coexisting species were likely to differ in body size or locomotor adaptations. Larger predators are capable of taking larger prey, thus effecting some dietary separation. Differences in locomotory abilities (such as climbing, endurance running) can also reduce overlap in prey choice through differences in habitat preference. Perhaps more importantly, they can allow one predator to escape from another, such as when leopards climb to avoid more-terrestrial lions, hyenas, and wild dogs (Van Valkenburgh 1985).

Further evidence of the potential role of interspecific competition in shaping the morphology of sympatric carnivores comes from the work of Dayan and colleagues (Dayan et al. 1989a,b, 1990, 1992; Dayan and Simberloff 1994). In studies of several suites of sympatric species, including mustelids, canids, and felids, they found evidence of remarkably even size separation between species in various features, such as canine tooth length (felids) or lower molar length (canids, mustelids). They argue that such even size separation does not occur by chance and is better explained as divergence due to competition for food. Similarly, Kiltie (1988) found that differences in jaw length among sympatric neotropical cats were fairly constant and suggested that this reflected differences in maximum jaw gape and thus prey size.

This discussion of ecological separation and morphological divergence among sympatric mammalian carnivores was intended to engage the reader in considering how theropods might have coexisted. Among living carnivorans, almost all species larger than about $21 \mathrm{~kg}$ take prey much larger than themselves, whereas smaller species feed mostly on prey that is $45 \%$ or less of their body weight (Carbone et al. 1999). Using an energetic model, Carbone et al. (1999) argued that it becomes increasingly difficult to subsist on small prey items as predator body mass increases because of limitations on intake rate and foraging time. Thus because of their large body size, most theropods probably hunted prey as large or larger than themselves. Given this, we expect that carcass theft was worthwhile and battles over kills occurred. Moreover, larger theropods likely preyed on smaller ones and may have even eaten juveniles of their own species. Consequently, we might expect to find predatory adaptations, as well as adaptations to interspecific competition and intraguild predation, among sympatric carnivorous theropods that are similar to those of sympatric mammalian carnivores.

\section{Materials and Methods}

\section{The Sample}

Our guilds of predatory dinosaurs were defined to include all known theropods from a well-sampled geologic formation that could reasonably be assumed to have been sympatric in time and space. We excluded from the guild edentulous theropods (ornithomimosaurs, oviraptors), small putatively edentulous theropods (elmisaurids), and those with non-sectorial teeth (therizinosaurids) on the assumption that these taxa were not feeding regularly on large prey. Although we are uncertain of their diets, the differences in their morphology from that of the presumably hypercarnivorous theropods do not suggest that they were exploiting "the same class of environmental resources in a similar way" (Root 1967). We will, however, mention their occurrences. We also did not include crocodilian or avian species, but we do not consider them to have been major competitors of the large terrestrial theropods that form the focus of this analysis. Furthermore, although the teeth of many theropods, carnivorous "thecodonts," ziphodont crocodilians, and varanoids, and even the canines of some sabercats are basically similar in form (Farlow et al. 1991), the teeth of other crocodilians-such as those found in the faunas we examine-seem to be different. Specifically, in this instance the crocodile teeth are unserrated and rounded in section, not compressed as are most theropod teeth (Molnar personal observation). Varanoids are not included, both because of the scarcity of their fossils and because the plesiomorphic forms appear not to have been predators on relatively large prey (Losos and Greene 1988).

Because we wished to compare species richness and ecological diversity in dinosaurian 
and mammalian guilds, we chose paleofaunas that included both small and large theropods, suggesting that many of the theropods that coexisted might be represented. This limited our choices to three well-sampled paleofaunas, the Morrison (Late Jurassic, western United States and Canada), the Judith River (Late Cretaceous, Canada), and the Nemegt (Late Cretaceous, Mongolia) (Table 1). Given that it is unlikely that all theropods that existed have been preserved or discovered for each of these faunas, we consider the guild lists to represent minimum numbers of coexisting species. It is possible that because of time and space averaging, the guilds include species that would have existed in different habitats or at different times, thus inflating actual guild size. However, the species are of large body size and presumably large home range (as is typical of extant large carnivorous mammals [see Gittleman and Harvey 1982; Farlow 1993]), and so we assume that there was spatial overlap among them. The question of temporal overlap is discussed below in each of the paleoguild descriptions.

The Morrison Guild.-The Morrison fauna derives from the Morrison Formation of the western United States, from Montana to New Mexico and from Oklahoma to Utah, which was deposited in Late Jurassic (Kimmeridgian and Tithonian) times (Turner and Peterson 1999). The theropod fauna includes three large (estimated weight greater than $1000 \mathrm{~kg}$ ), one moderately large (estimated 500-1000 kg), two moderately small (100-500 kg), and four small (less than $100 \mathrm{~kg}$ ) taxa. There is no reason to infer that any one of these was edentulous. The large taxa include Allosaurus fragilis, Torvosaurus tanneri, and Saurophaganx maximus: the first two are relatively well known, and estimated at approximately the same weight. The larger S. maximus is less well known, and cranial remains have not yet been found. It appears to have been less abundant than the others. The moderately large theropod is Ceratosaurus, known from several specimens assigned to three species (C. nasicornis, C. magnicornis, C. dentisulcatus) (Gilmore 1920; Madsen and Welles 2000). Fossils of Ceratosaurus are clearly less abundant than those of $A l$ losaurus, suggesting that this may have been
TABLE 1. Theropod species included in this paper listed by paleofauna. Body mass estimates are not shown for edentulous theropods (indicated by ${ }^{*}$ ) because they are presumed not to have been predators of large prey and thus were excluded from the allometric and guild analyses. The Hell Creek species were excluded from the guild analyses because theropod species richness in this paleofauna appears depauperate. Faunal composition data are from Weishampel (1990). Sources for body mass estimates: (1) Paul 1988 (estimated by immersion of scale models, details in Paul 1988:234-235); (2) Colbert 1962 (estimated by immersion of scale models); (3) Chure 1995 (using the formula published in Anderson et al. 1985); (4) original estimate (based on comparison with similar-sized, better-known taxa); (5) original calculation (after Anderson et al. 1985).

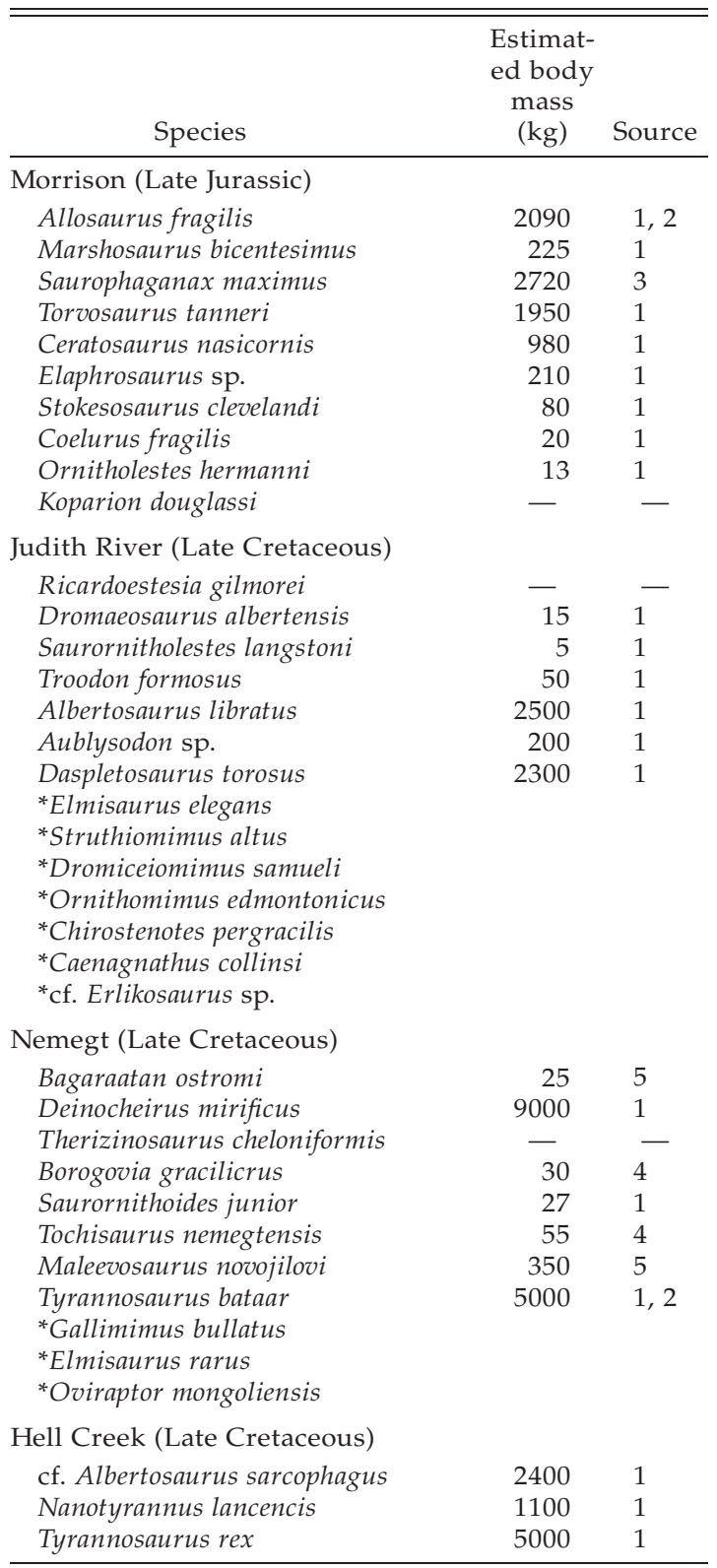


true of the living animals, although it could reflect taphonomic bias. Allosaurus is the most common of the theropods, making up more than $60 \%$ of all theropod specimens (Foster and Chure 1998). The smaller forms are also rare as fossils. Of the moderately small forms, Elaphrosaurus sp. is represented by only very rare elements and Marshosaurus bicentesimus is also uncommon, although not as rare as Elaphrosaurus. Likewise, the small forms are uncommon. Koparion douglassi, believed to be a primitive troodontid (Chure 1994), is known only from teeth, whereas Ornitholestes herman$n i$ is represented by a single skeleton (and an additional manus), Coelurus fragilis by a single partial skeleton (and rare additional pieces), and Stokesaurus clevelandi by rare isolated pieces. To some extent this rarity is probably due to taphonomic bias, the more fragile bones of the smaller theropods being less likely to be preserved, but collecting bias and bias toward studying large specimens may also have been involved in the late nineteenth and early twentieth centuries.

Turner and Peterson (1999) divided the Morrison into four zones deposited over about 8 million years, from the Kimmeridgian into the basal Tithonian. Koparion is found only in zone 4 (the youngest) and all of the other species are found in zones 2 and 3 (zone 1 yields only Allosaurus sp.). Allosaurus fragilis, Ceratosaurus nasicornis, and Coelurus fragilis have been found in both zones; Marshosaurus bicentesimus and Stokesosaurus clevelandi are from zone 3; and Torvosaurus tanneri, Ornitholestes hermanni, Elaphrosaurus sp., and Marshosaurus $\mathrm{sp}$. are found in zone 2 . There are three radiometric dates for the Morrison, $154 \mathrm{Ma}$ for the base of zone 1, $150 \mathrm{Ma}$ for the base of zone 3, and $149 \mathrm{Ma}$ for the base of zone 4 (Turner and Peterson 1999). Our focus is on zones 2, 3, and 4 , and thus the time span represented is estimated to be 2-4 Myr.

The Judith River Guild. - The Campanian Judith River Formation of the Montana-Alberta region has yielded a number of theropod taxa, some rather better known than others (see Dodson 1983). This unit dates to about 75 million years ago, and seems to have been deposited over a rather shorter period of time than the Morrison (Eberth et al. 1992). In the fauna, we recognize seven carnivorous theropods that probably took large prey and seven edentulous theropods that were unlikely to have regularly hunted large prey (Table 1). Of the carnivorous forms, Albertosaurus libratus and Daspletosaurus torosus are represented by substantial or complete skeletons. Dromaeosaurus albertensis, Saurornitholestes langstoni, Troodon formosus, and Ricardoestesia gilmorei are known from more limited material. Aublysodon sp. is represented in the Judith River by isolated teeth, although known from fragmentary skeletal remains from other regions. Among the edentulous forms, Struthiomimus altus, Dromiceiomimus samueli, and Ornithomimus edmontonicus are represented by substantial or complete skeletons. Caenagnathus collinsi, Elmisaurus elegans, Chirostenotes pergracilis (possibly synonymous with Caenagnathus [Currie and Russell 1988]), and cf. Erlikosaurus sp. are known only from incomplete specimens. The 14 species divided into three distinct groups by estimated weight. The large forms weighed over $2000 \mathrm{~kg}$, and include Albertosaurus and Daspletosaurus. The intermediate forms (Struthiomimus, Dromicieomimus, and Ornithomimus) weighed 100-200 kg, and the small forms weighed less than $100 \mathrm{~kg}$. These included Caenagnathus, Chirostenotes, Elmisaurus, Troodon, Dromaeosaurus, Saurornitholestes, and cf. Erlicosaurus.

Information on the stratigraphic occurrences of these taxa is less easily available than for the Morrison, but Dodson (1971) provided information for the outcrop of the Dinosaur Provincial Park in Alberta. Dromicieomimus was found higher in the section than Struthiomimus, but as only a single specimen of each was recorded, this may not be significant. Caenagnathus occurred throughout the section, as did Albertosaurus libratus, but the single specimen of Daspletosaurus torosus was found near the bottom of the beds. Dodson suggested, because of their rarity, that the small theropods "habitually inhabited other environments in other areas" (p. 68), unlike Albertosaurus and the ornithomimosaurs.

The Nemegt Guild.-Similar information for the Nemegt Formation of Mongolia appears not to be readily available. The age is not accurately known but is generally taken to be 
Campanian or Maastrichtian. We recognize eight carnivorous forms and three noncarnivorous theropods from this paleofauna. The distribution by estimated weight is similar to that for the Judith River. Large forms (over $2000 \mathrm{~kg}$ ) include Tyrannosaurus bataar and probably Deinocheirus mirificus and Therizinosaurus cheloniformis, both known only from quite incomplete material. Both Deinocheirus and Therizinosaurus are presumed carnivorous in this paper, but we recognize that this diagnosis could change with the discovery of craniodental remains. The two intermediate species are estimated to weigh between 200 and $500 \mathrm{~kg}$ and include Maleevosaurus novojilovi, a carnivore, and Gallimimus bullatus, an edentulous putative omnivore. The small forms probably weighed $100 \mathrm{~kg}$ or less and include an edentulous, presumably non- or weakly carnivorous species (Oviraptor mongoliensis), and highly carnivorous taxa (Saurornithoides junior, Borogovia gracilicrus, Tochisaurus nemegtensis, and Bagaraatan ostromi). An additional small species, Elmisaurus rarus, whose skull and teeth are unknown, is here assumed to have been edentulous based on its possible sister-taxon relationship to the Oviraptosauria (Currie 1990). Only T. bataar, M. novojilovi, and G. bullatus are known from reasonably complete or complete skeletons; the others are represented by less or much less complete rare material. Data from the PolishMongolian expeditions (Gradzinski et al. 1968; Gradzinski and Jerzykiewicz 1972) indicate that Tyrannosaurus bataar and ornithomimid (presumably Gallimimus bullatus) remains have a broad stratigraphic range through the beds.

Mammalian Guilds.-The three theropod guilds are compared with seven previously studied mammalian predator guilds. Four of these are extant: Serengeti (East Africa), Malaysia, Chitawan (Nepal), and Yellowstone (North America). The remaining three are extinct North American guilds: (1) Orellan, 34$32 \mathrm{Ma}$; (2) Irvingtonian, 1.7-0.7 Ma; and (3) Rancholabrean, 0.7-0.01 Ma. The fossil guilds were included because it is clear that extant predator guilds are depauperate as a result of the late Pleistocene extinction event. More detailed descriptions of these guilds, including taxonomic composition and environmental characteristics, are given by Van Valkenburgh $(1985,1988,1989,1991)$ and Van Valkenburgh and Hertel (1998). The guilds were defined to include all species larger than $7 \mathrm{~kg}$ that were predatory and potentially competed for food.

\section{Data Analysis}

Comparisons of predatory adaptations in theropods and mammalian carnivores were made using least-squares regression of $\log _{10}$ transformed measurements, including skull length, snout width, tooth length, jaw depth, and jaw length. The data for the sampled mammals and theropods are derived from previous publications as noted in the text and relevant figure captions.

Species richness was estimated as the total number of species within each guild. Body size distributions within guilds were compared by using Barton-David (B-D) statistics (Barton and David 1956; Simberloff and Boecklen 1981). B-D statistics test whether size differences between successively sized species are more similar than expected by chance. If they are, and if they approach some constant, the result is usually assumed to reflect character displacement (see Dayan et al. 1989a,b). To test for size ratio constancy, body mass estimates for each species within a guild were ordered from smallest to largest and $\log _{10}$ transformed. The differences in $\log _{10}$ transformed mass values between successively sized species within a guild are the size ratio data. The B-D statistic used here, G, is the ratio of the smallest to the largest size ratio within each guild. Probability estimates for G-values are estimated as described in Barton and David (1956).

\section{Results and Discussion}

\section{Comparative Morphology}

We begin our comparison of dinosaurian and mammalian predatory guilds with an examination of the array of predatory types apparent in each group. As noted above, guilds of mammalian carnivorans (members of the order Carnivora) typically contain highly carnivorous species (e.g., felids, some canids), more omnivorous species (e.g., most canids, 
some ursids), and perhaps bone crackers (e.g., hyaenids). Can we find these same ecomorphs among dinosaurs in general and theropods in particular? Apparently not, in that the bonecrackers and probably the more omnivorous forms seem to be missing from dinosaur communities. This claim is based on the relative lack of dental diversity among theropods. With the exception of theriznosaurids and edentulous species, all theropods considered here with known cranial material are relatively similar in tooth form. Although the teeth may vary in size along the theropod tooth row, they all are shaped somewhat like the canine teeth of carnivorans and would have been of limited use for grinding plant matter or cracking large bones regularly (Farlow et al. 1991). It is clear that theropod teeth occasionally contacted bone in killing and/or feeding as evidenced by various punctures and scores on the preserved bones of their prey and a large coprolite containing many bone fragments, but there is no evidence of significant gnawing (Currie and Jacobsen 1995; Erickson and Olson 1996; Chin et al. 1998). Moreover, a survey of tooth-damaged bone in six dinosaur localities found very little evidence of bone crushing, supporting the idea that habitual consumption of large bones was rare (Fiorillo 1991). These findings suggest that all theropods with sectorial teeth were highly carnivorous (hypercarnivorous) and that ecological separation among coexisting taxa would have depended on differences in habitat choice, prey size, or prey type. The diet of the edentulous forms is unclear, but a recent discovery of gastroliths in an undescribed Chinese ornithomimosaur may indicate a herbivorous/granivorous diet for at least this species (Kobayashi et al. 1999). Previous work with stable nitrogen isotope analysis did not find a significant difference in values between North American ornithomimosaurs and clearly carnivorous theropods such as tyrannosaurids and dromaeosaurids (Ostrom et al. 1993). However, only two values were obtained, one similar to that for ceratopsians and the other greater than that of the dromaeosaurid examined. The ornithomimosaurs may have had a catholic diet, like living foxes or bears, or different species may have specialized in different foods, but they certainly do not appear to have been highly carnivorous.

In theropods, the absence of strongly heterodont dentitions such as are typical of omnivorous mammals might reflect the limited resources that were available. Omnivorous carnivorans rely fairly heavily on fruits for part or most of the year (Ewer 1973; Van Valkenburgh 1989), and fruits of significant size ( $>5 \mathrm{~cm}$ diameter) that likely depended on biotic dispersal were not common until the latest Mesozoic (Tiffney 1984; Wing and Tiffney 1987). Among living carnivorans, the ability to crack bones allows access to marrow, including fat deposits (see Haynes 1982). It is not clear that dinosaur bones, which are often pneumatic in saurischians, contained a highly nutritious marrow, and if not, the major benefit of bone cracking would have been nonexistent. Thus, the limited carnivorous nature of theropod dental morphology is appropriate for the predominant food (dinosaurs) that was available to nonherbivorous species. Alternatively, the lack of differentiation in theropod dentitions might reflect constraints on tooth form imposed by the nature of their development. Theropod teeth are replaced multiple times over their life span and thus the tooth row always contains teeth of varying age and height. Consequently precise tooth-to-tooth occlusion between any pair of opposing upper and lower teeth is difficult to sustain, and thus the evolution of more complex teeth may not have been favored.

Comparisons of the postcranial adaptations for hunting and killing in dinosaurs and carnivorans reveal few similarities. Among extant large carnivorans, there are short-distance ambush species (e.g., felids, some ursids) that use their muscular forelimbs and clawed feet to grapple with prey while they administer a deadly bite. Alternatively, there are those that are incapable of grappling, and instead kill with jaws alone after a long-distance pursuit (e.g., canids, hyaenids). Two comparable types can be recognized among theropods, "head-hunters" and "grappler/ slashers." Presumably, the head-hunters were the allosaurs, later ceratosaurs, and tyrannosaurs, all relatively large species with reduced 
forelimbs and no evidence of enlarged pedal claws. These species killed through actions of their jaws and teeth with little or no assistance from their forelimbs. The best developed grappler/slashers were the dromaeosaurs, agile theropods of small to medium size with well-developed, clawed forelimbs and slashing pedal claws. No doubt, these species used both hands and feet to produce mortal wounds, as felids will in some circumstances. Coelurosaurs and troodontids lacked the large, terrible claws of dromaeosaurs and can be considered less well equipped grapplers that almost always took prey smaller than themselves.

The two different killing styles in theropods are not so clearly associated with different hunting modes (ambush vs. long-distance pursuit) as they are in carnivorans. On the one hand, the light build of most of the grappler / slashers suggests speed, and therefore the potential for long-distance pursuit. Their moderate size, however, would also have made them excellent ambush predators, as they could be concealed fairly easily in dense vegetation. On the other hand, many or all of the head-hunters were so large as to make ambush hunting seem ludicrous. What could a $T$. rex hide behind? Although dense vegetation might conceal a T. rex, could such a large animal move through it quietly enough to stalk its prey? If ambush was not an option, then the tyrannosaurs must have overtaken their prey, although this was probably done with a fast walk rather than a run (Farlow et al. 1995; Carrano 1999; Hutchinson and Garcia 2002).

Although qualitative comparisons of theropod and carnivoran adaptations can be stimulating, it is more satisfying to establish similarities in structure based on quantitative data. Fortunately, recent studies of the allometry of teeth, jaws, and skulls of mammalian carnivores allow for some direct comparison of scaling relationships between mammalian and dinosaurian predators. The data presented here are limited, in that only a subset of theropod diversity is represented and comparisons were constrained by the availability of similar data (e.g., measures of jaw depth or length) for both groups. Because we were interested in examining sympatric suites of the-

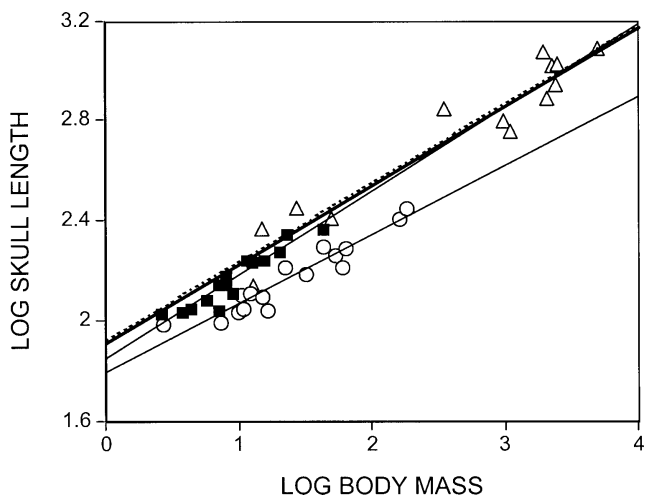

FIGURE 1. $\log _{10}-\log _{10}$ plot of maximum skull length $(\mathrm{mm})$ against body mass $(\mathrm{kg})$ for canid (solid squares, $n$ $=17$ ), felid (open circles, $n=16$ ), and theropod (triangles, dashed line, $n=14$ ) species. Linear regression equations: for canids, $\log _{10} \mathrm{y}=1.85+0.332\left(\log _{10}\right.$ body mass), $r^{2}=0.89, p<0.001$; for felids $\log _{10} \mathrm{y}=1.8+0.273$ ( $\log _{10}$ body mass), $r^{2}=0.9, p<0.001$; for theropods, $\log _{10}$ $\mathrm{y}=1.92+0.314\left(\log _{10}\right.$ body mass $), r^{2}=0.93, p<0.001$. Data for canids are from Van Valkenburgh and Koepfli (1993); data for felids are from Van Valkenburgh and Ruff (1987). Data for theropods are from Osborn (1916), Gilmore (1920, 1946), Colbert (1962), Russell (1970), Barsbold (1974), Maleev (1974), Paul (1988), and Britt (1991).

ropods, our sample is confined to 28 species from four formations, the Morrison (Late Jurassic), Judith River (Late Cretaceous), Hell Creek (Late Cretaceous), and Nemegt (Late Cretaceous) (Table 1). The Hell Creek assemblage was not included in our paleoguild comparisons because it has only three species as opposed to the 10-14 for the included assemblages, and this suggests that it is likely to be missing species that were present. In fact, one of the three species, Nanotyrannus lancensis, may be a juvenile T. rex (Carr 1999), leaving only two theropods in the Hell Creek. We include the Hell Creek species in the allometric analysis to expand the sample of theropods for comparison with mammals. An even larger sample of theropod species might strengthen our conclusions and we would like to expand the analysis in the future. Nevertheless, we feel that the 28 sampled species are broadly representative of the diversity of theropod craniodental morphology.

Relative Head Size.-Relative head size varies among extant large carnivorans (Fig. 1). Felids have small heads relative to their body mass, both because their bodies tend to be fairly heavily muscled and because their skulls are 


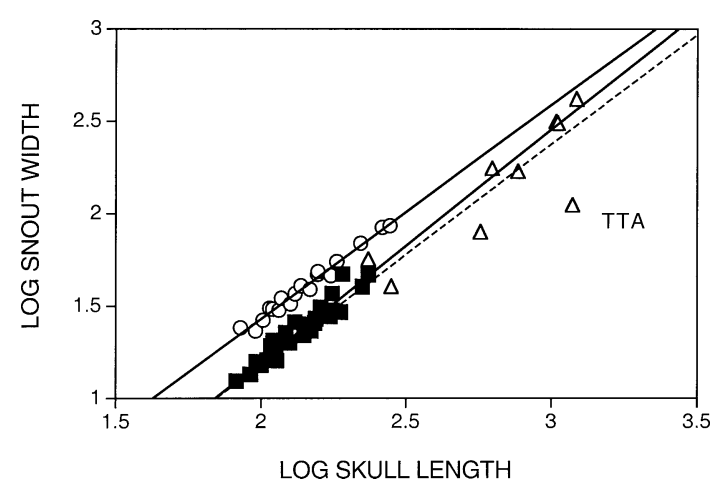

FIGURE 2. $\log _{10}-\log _{10}$ plot of maximum snout width $(\mathrm{mm})$ against skull length $(\mathrm{mm})$ for canids (solid squares, $n=33$ ), felids (open circles, $n=18$ ), and theropods (triangles, dashed line, $n=10$ ). Linear regression equations: for canids, $\log _{10} \mathrm{y}=-1.14+1.26\left(\log _{10}\right.$ skull length), $r^{2}=0.92, p<0.001$; for felids $\log _{10} \mathrm{y}=$ $-0.89+1.16, r^{2}=0.98$; for theropods, $\log _{10} \mathrm{y}=-1.2+$ 1.19 ( $\log _{10}$ skull length), $r^{2}=0.74, p<0.01$. Data for canids are from Van Valkenburgh and Koepfli (1993); felids were measured for this paper. Data for theropods as in Figure 1.

somewhat small. Canids on the other hand have relatively larger skulls and more slender bodies. The difference is most pronounced among species of large size and reflects killing behavior to some extent. Felids tend to kill with a single, strong bite to the neck or muzzle, whereas canids tend to use repeated, shallower bites to subdue their prey. The short snout of felids enhances the leverage of their jaw muscles for a killing bite with the canines by reducing the moment arm of resistance of an anteriorly placed load (Biknevicius and Van Valkenburgh 1996). Theropods were proportioned more like canids (Fig. 1). With the exception of the small coelurosaur Ornitholestes hermanni, all sampled theropods have relatively larger skulls than felids of similar body mass. Thus, we do not see a clear division of theropods into the two alternative killing types that are apparent today. Rather, they all appear to have been built fairly similarly and there is little or no evidence of catlike theropods in our sample. It would be interesting to be able to include more taxa, especially smaller species.

Skull Shape.-A comparison of skull shape among canids, felids, and theropods reveals additional similarities between canids and theropods (Fig. 2). Felids have broader snouts relative to skull length than either canids or theropods. Maximum muzzle width is positively allometric in all three groups, with larger species exhibiting relatively broader muzzles. The smallest theropods for which we have data overlap canids on the plot of maximum snout width against skull length. The relationship of snout width to skull length in theropods is close to isometry (1.19), but our sample size is quite small $(n=10)$, and the $95 \%$ confidence interval for the slope is large (0.62-1.76). In canids, the broader muzzle of larger species was correlated with enlarged canine and incisor teeth and with diets that include relatively large prey (Van Valkenburgh and Koepfli 1993). For example, wolves, dholes, and African hunting dogs often take prey larger than themselves, whereas similarsized canids such as the maned wolf or Ethiopian wolf are more narrow-snouted and tend to hunt small prey (e.g., lagomorphs and rodents). Theropods may have been similar, with the largest forms such as the tyrannosaurids tackling the most difficult prey. Notably, the large theropod Torvosaurus tanneri has a very narrow snout for its skull length (TTA in Fig. 2), suggesting it may have had a weaker bite and might have favored smaller prey than similar-sized tyrannosaurs.

Relative Tooth Size.-Because of the absence of specific serial homology between the teeth of theropods and mammals, it is difficult to compare them in terms of relative tooth size. It is not clear whether one should compare theropod cheek teeth to the premolars or carnassials of carnivorans, for example. We chose the carnassials because they are usually the largest teeth in the jaw and function somewhat similarly in felids and canids. A comparison of the largest lower teeth of theropods with the lower carnassials of canids and felids reveals that the teeth of theropods are substantially shorter mesiodistally than those of canids and felids of similar jaw length (Fig. 3). The large carnosaurs and tyrannosaurs also appear to have shorter teeth than would be expected for a mammalian carnivore of their body size. This is not surprising given that theropod jaws contain many more teeth, all of more similar size, than do jaws of mammals. Although felids and canids appear to be similar in tooth length/jaw length proportions, 


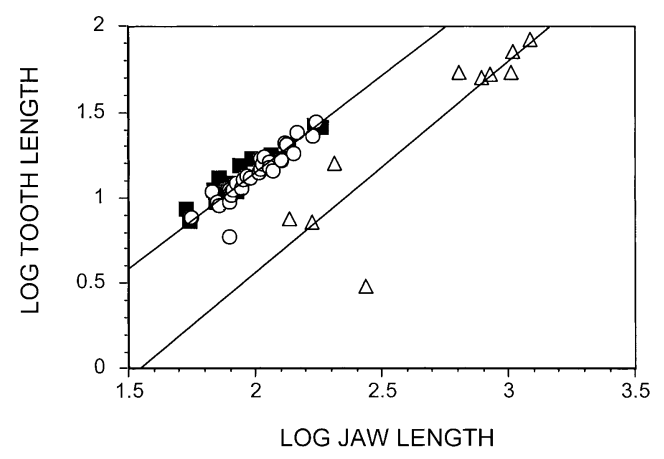

FIGURE 3. $\quad \log _{10}-\log _{10}$ plot of the mesiodistal length of the longest lower tooth $(\mathrm{mm})$ against maximum jaw length $(\mathrm{mm})$ for canid (solid squares, $n=32$ ), felid (open circles, $n=16$ ), and theropod (triangles, $n=10$ ) species. For canids and felids, the lower first molar was used. Linear regression equations: for canids and felids together, $\log _{10} \mathrm{y}=-0.93+1.05\left(\log _{10}\right.$ jaw length $), r^{2}=$ $0.85, p<0.001$; for theropods, $\log _{10} \mathrm{y}=1.94+1.25\left(\log _{10}\right.$ jaw length), $r^{2}=0.77, p<0.01$. For data sources, see Figure 1.

the slopes of the log-log regressions differ significantly, with canids showing positive allometry as opposed to near isometry in felids. Interestingly, theropods also show positive allometry with larger species displaying even larger teeth (slope $=1.25$ ). However, our sample size for theropods is small and the addition of more species could easily alter the apparent positive relationship.

Relative Jaw Depth.-The ratio of jaw depth to length should be indicative of jaw strength during biting. Although it would be preferable also to include information on jaw width and cortical bone distribution internally as has been done for carnivorans (Biknevicius and Ruff 1992), few data are available for theropods. When tetrapods bite an object, their jaws are loaded somewhat as beams with the jaw joint acting as a fulcrum. Bending strength is enhanced by deepening the jaw relative to its length, and consequently, carnivorans such as the bone-cracking hyenas have relatively deep jaws. Here we compare jaw depth taken midway along the tooth row of theropods with previously published data on maximum depth in carnivorans (canids, felids, hyaenids). Maximum jaw depth in carnivorans tends to occur posterior to the midpoint of the tooth row, near the carnassials. Although it might have been preferable to compare maximum jaw depth in both groups,

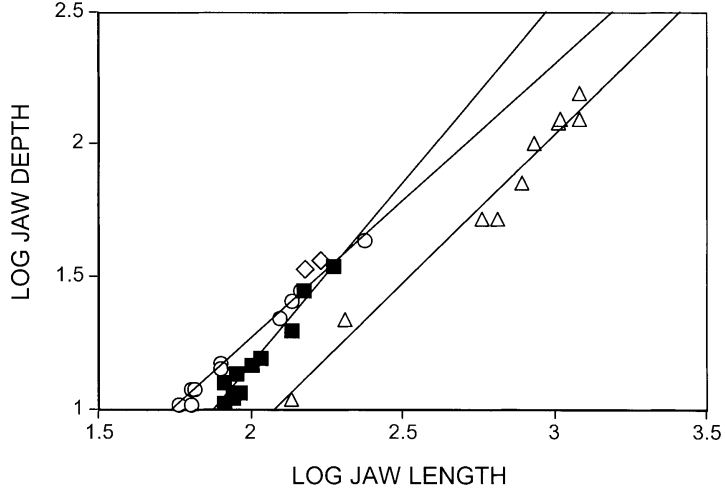

FIgURE 4. $\log _{10}-\log _{10}$ plot of jaw depth (mm) against maximum jaw length $(\mathrm{mm})$ for felids (open circles, $n=$ 10 ), canids (solid squares, $n=10$ ), hyaenids (diamonds, $n=2$ ), and theropod (triangles, $n=10$ ) species. Jaw depth is measured at the midpoint of the tooth row in theropods, and as the maximum depth along the tooth row in carnivorans. Linear regression equations: for felids, $\log _{10} \mathrm{y}=-0.8+1.04\left(\log _{10}\right.$ jaw length), $r^{2}=0.99$, $p<0.001$; for canids, $\log _{10} \mathrm{y}=-1.57+1.37\left(\log _{10}\right.$ jaw length), $r^{2}=0.95, p<0.001$; for theropods, $\log _{10} \mathrm{y}=$ $-1.33+1.22\left(\log _{10}\right.$ jaw length), $r^{2}=0.97, p<0.001$. Data for carnivorans are from Biknevicius and Ruff (1992). Data for theropods are from Osborn (1916), Gilmore (1920, 1924), Russell (1969, 1970), Colbert and Russell (1969), Barsbold (1974), Maleev (1974), Britt (1991), Carpenter (1992), Osmolska (1996), and Glut (1997).

maximum depth in theropods occurs behind the tooth row in the region where jaw adductor muscles insert. Because we are interested in the strength of the jaw when biting, we chose the tooth-row midpoint as a reasonable position for the estimation of jaw rigidity.

Despite the potential problems of comparing non-analogous measures, a log-log regression of jaw depth on length for carnivorans and theropods reveals similar scaling relationships, with both groups showing positive allometry (slope $=1.12$, theropods; 1.04 felids; 1.37, canids; Fig. 4). The slopes of the regression lines are not significantly different between theropods and felids (ANCOVA: $p=$ $0.357)$, theropods and canids(ANCOVA: $p=$ 0.137), or theropods against all 22 carnivoran species (ANCOVA: $p=0.894$ ). Apparently, however, the jaws of theropods were relatively weaker for their length than those of carnivorans. The positive allometry in both groups suggests that larger species loaded their jaws more heavily, because deeper jaws are much stronger in resisting loads applied dorsoventrally, as during jaw closure. This component 
of jaw strength is largely dependent on jaw depth and increases approximately with the square of depth (see Biknevicius and Van Valkenburgh 1996 for details). As was the case for muzzle width, the positive allometry of jaw depth suggests that larger theropods killed prey that were very large relative to their own body size. Thus, the data presented here suggest that the jaws of Tyrannosaurus rex were at least as strong as and probably relatively stronger than those of other carnosaurs, and do not support the idea that T. rex was a less capable killer and relied more on scavenging than other carnosaurs (see also Erickson et al. 1996; Molnar 2000).

The fact that theropods appear to have had weaker jaws than similarly sized carnivorans might be explained by our choice of tooth row midpoint for the depth comparison. As noted above, the measure for carnivorans was taken posterior to the midpoint, and it is clear that theropod jaws do deepen behind the midpoint but beyond the end of the tooth row. To resolve this issue, it would be useful to compare jaw depth in carnivoran and theropod jaws at multiple positions in a more comprehensive analysis. In addition, it should be noted that theropod dentary bones are solid (Molnar 2000), whereas those of carnivorans have a medullary cavity. A solid dentary is somewhat stronger than a hollow one, but because strength in bending is enhanced more by increasing overall diameter, the carnivorans probably retain the stronger jaws. In the two examples where theropods and carnivorans overlap in size (Ornitholestes hermanni and Dromaeosaurus albertensis), carnivorans have jaws that are approximately twice as deep. Notably, a recent finite element analysis of cranial and bite strength in Allosaurus fragilis also found that this species had a relatively weaker bite than do carnivorans (Rayfield et al. 2001).

Jaw depth is significantly correlated with typical prey size in a limited sample of ten species of canids and felids (Fig. 5). If this regression is used to predict the typical prey of theropods, it produces overestimates, at least for those species that were much larger than any of the carnivorans used in the regression. For example, it predicts that Tyrannosaurus rex was usually killing prey that weighed $10^{6} \mathrm{~kg}$

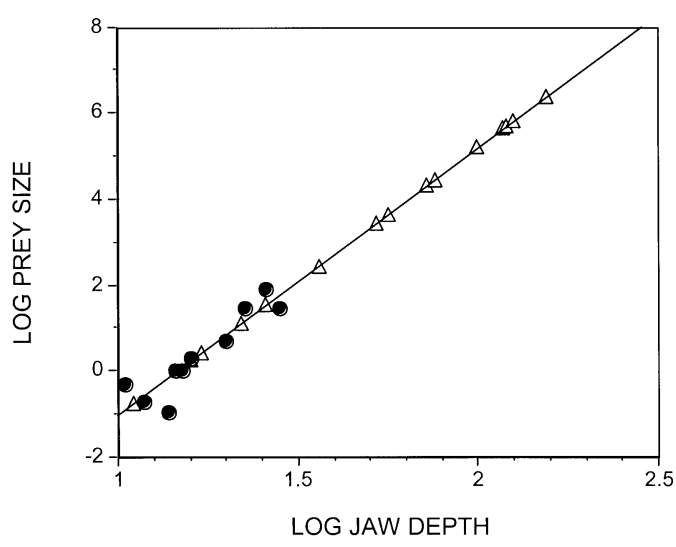

FIGURE 5. $\quad \log _{10}-\log _{10}$ plot of typical prey size $(\mathrm{kg})$ against maximum jaw length $(\mathrm{mm})$ for ten species each of canids and felids (solid circles). The linear regression equation derived from these data was used to estimate typical prey sizes of theropods (triangles) based on their estimated body masses. Linear regression equation for carnivorans $(n=10): \log _{10} \mathrm{y}=-7.25+6.22\left(\log _{10}\right.$ jaw length), $r^{2}=0.84, p<0.001$. Data for typical prey size of carnivorans are from Van Valkenburgh and Hertel (1998).

(one thousand tons), a size that exceeds the maximum weight estimates made for any dinosaur (Peczkis 1994). On the other hand, the prey size estimates for the three smaller theropods, Ornitholestes, Saurornithoides, and Dromaeosaurus, might be reasonable, as they are much more similar in size to the mammalian carnivores used for the regression. It is difficult to assign much confidence to any of these estimates given the differences in body form between dinosaurs and carnivorans. However, it is likely that there was a positive relationship between prey size and jaw depth in theropods, and consequently, jaw depth might be useful in examining ecological separation among sympatric theropods. Unfortunately, we could not do so because of the absence of jaw depth data for many of our species.

Species Richness. - The mammalian predator guilds include species whose diets range from omnivorous to hypercarnivorous and thus are not strictly comparable to the theropod guilds, which include putative hypercarnivores only. If the edentulous and presumably less carnivorous theropods are considered as part of the predator guild, then total species diversity is similar in both mammalian and theropod guilds (Fig. 6). The total number of species within the mammalian guilds ranges 


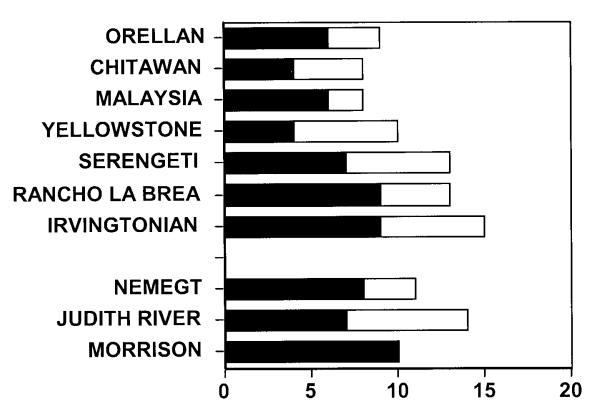

FIGURE 6. Species richness in theropod (Nemegt, Judith River, Morrison), extinct mammalian predator (Orellan, Irvingtonian, Rancholabrean), and extant mammalian predator (Yellowstone, Chitawan, Malaysia, Serengeti) guilds. Number of hypercarnivorous species is shown in black. For species composition of all mammalian guilds except the Rancholabrean, see Van Valkenburgh 1985, 1991. Rancholabrean guild includes Canis lupus, C. dirus, C. latrans, Smilodon fatalis, Homotherium serus, Panthera atrox, P. onca, P. concolor, Lynx rufus, Miracinonyx trumani, Arctodus simus, Ursus arctos, and $U$. americanus. All but the last three and C. latrans were considered hypercarnivorous. For species composition of theropod guilds, see Table 1.

from 8 (Malaysia, Chitawan) to 15 (Irvingtonian) with a mean of 11 . The mean diversity of the theropod guilds is also 11, with 14 species in the Judith River, 11 in the Nemegt, and 10 in the Morrison. If species richness of just the hypercarnivores is compared, theropod and mammalian guilds are also not significantly different, with an average of 6 hypercarnivores in mammalian guilds and 8 in the theropod guilds (Fig. 6). This is somewhat surprising for two reasons. First, as mentioned earlier, sympatric theropods appear more similar to one another than do sympatric hypercarnivorous mammals, and thus one would expect fewer species could coexist. Such a limit on co-occurrence is known to occur among some extant lizards, in that Varanus komodoensis, a hypercarnivore, appears to eliminate other, smaller varanids from its range (Auffenberg 1981). However, this does not appear to be true among the varanids of Australia (Pianka 1994). Second, given that there is typically a negative relationship between species diversity and body size (see Hutchinson and MacArthur 1959; Van Valen 1973), the larger mean body size of carnivorous theropods would be expected to be associated with reduced taxonomic diversity. Of course, this relationship is likely to be influ- enced by energetics; if the energetic needs of dinosaurs were reduced relative to mammals, a given environment might sustain a greater abundance and diversity of species.

Species richness values might be inflated for the theropod guilds relative to the mammalian guilds if time-averaging is more severe for the former. Each of the theropod guilds is derived from sediments that span at least $1 \mathrm{Myr}$ (Judith River) to as much as 4 Myr (Morrison). It is impossible to be certain that all the species listed as guild members were sympatric for some period of time, but given that vertebrate species typically last for about 2-4 Myr (Stanley 1979), it seems likely that they would have overlapped in time. Consequently, we do not feel that time-averaging explains the richness of the theropod faunas. Moreover, the extinct mammalian guilds (Orellan, Irvingtonian, Rancholabrean) also span millions of years and broad geographic areas. Spatial mixing of theropod species that were never contemporaneous but rather lived in the area at different times also seems unlikely. As mentioned before, large carnivores tend to have large home ranges and broad geographic distributions as a result of their metabolic requirements (see Gittleman and Harvey 1982; Farlow 1993) and this makes it difficult for species to avoid each other over extended time spans. Alternatively, theropod richness might be inflated because of taxonomic oversplitting relative to mammals. This is difficult to assess but would probably only decrease species richness by one or two taxa per guild. Most of the theropod species are readily distinguished from one another.

The theropod guild with the greatest number of hypercarnivorous species (ten) is the late Jurassic Morrison. If this is not due to taphonomic bias or oversplitting, the increased predator richness might reflect a greater availability of prey, as is the case for mammalian guilds. For example, of the four extant predator guilds, the Serengeti includes a greater number of species in total, as well as a greater number of hypercarnivores, and has by far the greatest biomass of prey (Van Valkenburgh 1989). Unlike the two Late Cretaceous faunas, the Morrison included several large sauropod species (Weishampel 1990) 
TABLE 2. Average size difference between adjacentsized species within guilds computed as the difference between $\log _{10}$ body mass estimates for each species. G1Barton-David statistic, the ratio of the smallest difference between species over the largest difference between species. $p=$ probability that the distribution of body size differences can be explained by chance.

\begin{tabular}{lccc}
\hline \hline \multicolumn{1}{c}{ Guild } & $\begin{array}{c}\text { Mean } \\
\text { size ratio }\end{array}$ & $\mathrm{G} 1$ & \multicolumn{1}{c}{$p$} \\
\hline Malaysia & 0.238 & 0.097 & 0.285 \\
Serengeti & 0.177 & 0.038 & 0.533 \\
Yellowstone & 0.257 & 0.068 & 0.743 \\
Chitawan & 0.344 & 0.10 & 0.648 \\
Rancholabrean & 0.202 & 0.151 & 0.063 \\
Irvingtonian & 0.149 & 0.179 & 0.154 \\
Orellan & 0.156 & 0.147 & 0.24 \\
Nemegt & 0.426 & 0.056 & 0.678 \\
Judith River & 0.54 & 0.113 & 0.707 \\
Morrison & 0.290 & 0.047 & 0.397 \\
\hline
\end{tabular}

and this could have favored a greater diversity of large theropods.

Body Size Diversity.-Predator body size is positively associated with prey body size (Van Valkenburgh and Koepfli 1993; Van Valkenburgh and Hertel 1998), and thus ecological separation among sympatric hypercarnivores can be effected by differences in body size. As noted above, studies of modern carnivore guilds have documented remarkably even spacing between species in the size of certain features, such as jaw length or tooth size (e.g., Dayan et al. 1992; Kiltie 1988). We would have liked to do the same sorts of quantitative analyses of the theropod guilds but the data are not sufficiently complete. Unfortunately, size ratio analyses are not useful when the same measurement is not available for all species within the guild. The only parameter for which we had nearly complete data was estimated body mass, and it has not been observed to show constant size ratios in modern carnivore guilds. Because the body mass data for theropods used here are estimates taken from the literature that were derived by different methods, our results must be viewed with caution.

For both carnivorans and theropods, size ratios were not constant within any guild, and B-D statistics indicate that the distribution of size ratios could be explained by chance (Table 2, Fig. 7). Unlike the mammal guilds, each of the three theropod guilds includes at least one pair or trio of very similarly sized species. It would be interesting to look for other evidence of character divergence within these clusters, such as differences in locomotor or feeding adaptations, as is apparent among mammals. For example, the Serengeti includes three species of similar mass-leopard, cheetah, and spotted hyena. Each of these is quite distinct morphologically and behaviorally. The hyena exploits carcasses more fully than either cat because of its bone-cracking abilities. The two cats separate by habitat and hunting style; the cheetah is a sprinter of more open country whereas the leopard is an ambusher that prefers gallery forest. By contrast, the trios and pairs of similar-sized theropods are not composed of combinations of head hunters and grappler/slashers. Instead, there is no overlap in size between these two; grappler/slashers always filled the low end of the size range.

The average difference between successively sized species among the seven mammalian predator guilds was $0.201(n=38, \mathrm{SD}=0.173)$ (Table 2$)$. The same value was larger $(0.399 ; n$ $=19, \mathrm{SD}=0.348$ ) for the three theropod guilds, and this difference was significant using a t-test $(F=8.275 ; p<0.01)$, but not using a Mann-Whitney nonparametric test $(p=$ $0.11)$. The nonparametric test is more appropriate given that ratio data are being compared, but it is much more conservative. Given that the sample size for theropods is much less than that for the mammals, the lack of statistical significance should not be considered as definitive. It does appear from examination of the distribution of body sizes within guilds that sympatric theropods tend to separate by size more than mammals (Fig. 7). This might reflect an increased pressure to segregate by size among theropods because of their overall similarity in body form. In addition, suites of sympatric theropods span a much greater range of body sizes than do those of mammals; consequently, there is more room to spread out.

In sum, theropod guilds do not seem to demonstrate ecological separation as clearly as do the mammalian guilds. Size separation is apparent, but when there is overlap, it is not clear how the species differ along another di- 

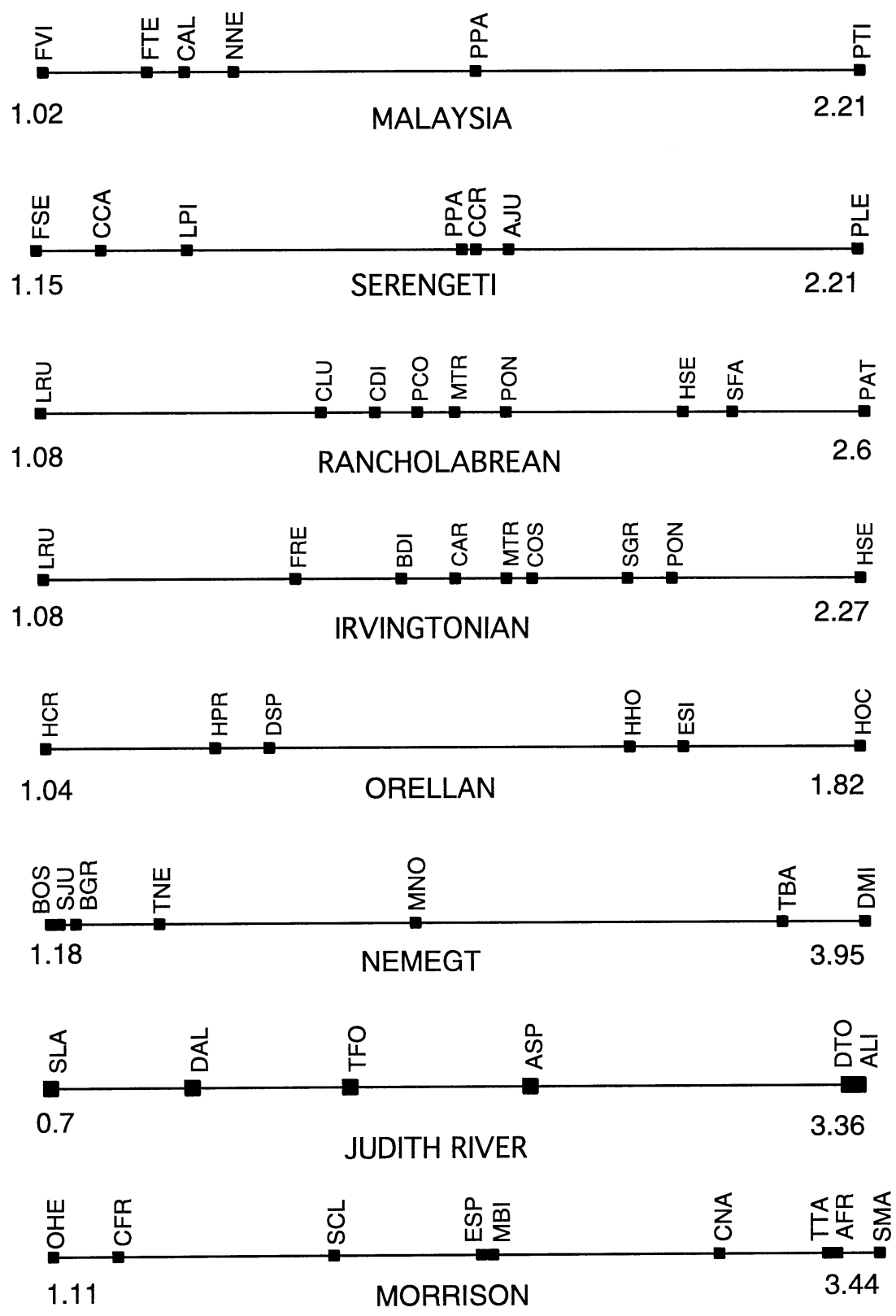

FIGURE 7. Body size $\left(\log _{10}\right)$ distribution of hypercarnivorous species in theropod and mammalian predator guilds. Species abbreviations: FVI = Felis vivverina; FTE $=$ F. temmincki; $\mathrm{CAL}=$ Cuon alpinus; $\mathrm{NNE}=$ Neofelis nebulosa; $\mathrm{PPA}$ $=$ Panthera pardus $; \mathrm{PTI}=$ P. tigris $; \mathrm{FSE}=$ F. serval $; \mathrm{CCA}=$ Caracal caracal $; \mathrm{LPI}=$ Lycaon pictus $; \mathrm{CCR}=$ Crocuta crocuta; $\mathrm{AJU}=$ Acinony $x$ jubatus; $\mathrm{PLE}=$ P. leo $; \mathrm{LRU}=$ Lynx rufus; $\mathrm{CLU}=$ Canis lupus $; \mathrm{CDI}=\mathrm{C}$. dirus; $\mathrm{PCO}=$ Puma concolor; MTR $=$ Miracinony $x$ trumani $; \mathrm{PON}=$ Panthera onca $; \mathrm{HSE}=$ Homotherium serus $; \mathrm{SFA}=$ Smilodon fatalis $;$ PAT $=$ Panthera atrox; FRE $=$ Felis (?) rexroadensis; $\mathrm{BDI}=$ Borophagus diversidens; $\mathrm{CAR}=$ Canis armbrusteri $;$ COS $=$ Chasmoporthetes ossifragus; $\mathrm{SGR}=$ Smilodon gracilis; $\mathrm{HCR}=$ Hyaenodon crucians; $\mathrm{HPR}=$ Hoplophoneuus primaevus; DSP $=$ Dinictis sp.; $\mathrm{HHO}=$ Hyaenodon horridus; $\mathrm{ESI}=$ Eusmilus sicarius $; \mathrm{HOC}=$ Hoplophoneus occidentalis $; \mathrm{BOS}=$ Bagaraatan ostromi; $\mathrm{SJU}$ = Saurornithoides junior $; \mathrm{BGR}=$ Borogovia gracilicrus; $\mathrm{TNE}=$ Tochisaurus nemegtensis $; \mathrm{MNO}=$ Maleevosaurus novojilovi; TBA = Tyrannosaurus bataar; DMI = Deinocheirus mirificus; $\mathrm{SLA}=$ Saurornitholestes langstoni; DAL $=$ Dromaeosaurus albertensis; $\mathrm{TFO}=$ Troodon formosus $; \mathrm{ASP}=$ Aublysodon sp.; $\mathrm{DTO}=$ Daspletosaurus torosus; $\mathrm{ALI}=$ Albertosaurus libratus; $\mathrm{OHE}=$ Ornitholestes hermanni; $\mathrm{CFR}=$ Coelurus fragilis; $\mathrm{SCL}=$ Stokesosaurus clevelandi; $\mathrm{ESP}=$ Elaphosaurus sp.; $\mathrm{MBI}=$ Marshosaurus bicentesimus; $\mathrm{CNA}=$ Ceratosaurus nasicornis; $\mathrm{TTA}=$ Torvosaurus tanneri; $\mathrm{AFR}=$ Allosaurus fragilis; SMA = Saurophaganax maximus. 
mension. In large part this is due to a lack of comparable information; it is rare to find reasonably complete cranial, dental, and limb data for dinosaurs because the material is too fragmentary. Some species are known only from teeth and jaws, others from limb elements. As a result, we could not examine theropod guilds using a multidimensional morphospace as has been done with carnivorans (cf. Van Valkenburgh 1985, 1988, 1991). Nevertheless, the interspecific differences would seem to be subtler than those between sympatric carnivorans. As has been pointed out above, dental diversity is limited among theropods, and major postcranial differences lie in the relative size of the forelimbs (i.e., grappler/slasher vs. head hunter).

\section{Summary and Conclusions}

Our admittedly preliminary look at the structure of dinosaurian and mammalian predator guilds revealed some intriguing results that deserve further investigation with an expanded sample of theropods and more morphological data. The allometric comparisons demonstrated a surprising similarity between carnivorans and theropods in the scaling of jaw depth with length that suggests similar biomechanical constraints. In addition, theropods and carnivorans shared the tendency to show positive allometry in the scaling of most craniodental measures, suggesting that in both groups, larger species kill relatively larger prey. However, theropods could not be shoehorned into doglike, hyenalike, or catlike roles. Instead, they all appear more similar in their skulls and teeth than their mammalian counterparts. Other than the edentulous species, most if not all theropods appear to have been hypercarnivorous, and this may reflect a Mesozoic dearth of alternative resources (fruits, nutrient-rich bone marrow) used by some mammalian predators.

Theropod predator guilds included at least as many species as comparable mammalian predator guilds. This was not expected given the aforementioned morphological and inferred ecological similarity among sympatric theropods, and the great size of most of the species. Coexisting theropods usually differed in body mass to a slightly greater degree than do coexisting carnivorans. These differences could have favored coexistence because larger species tend to take larger prey. The association between predator and prey body size is well established for a wide array of extant vertebrates (frogs, snakes, lizards, birds, mammals [Emerson et al. 1994]) and probably applied to dinosaurs as well. Notably, it is not unusual to find two or three similar-sized species of theropod in the same paleofauna that do not differ markedly in their locomotor or feeding anatomy. This contrasts with carnivoran guilds where similar-sized sympatric species usually do differ in either locomotor or feeding behavior.

It seems very likely that theropod guilds were characterized by interspecific battles over carcasses, intraguild predation, and the tendency of smaller species to avoid larger, more dominant species, all processes that are observed in mammalian predator guilds. Today's bullies of the Serengeti plains, lions and spotted hyenas, were paralleled by tyrannosaurs in Jurassic and Cretaceous ecosystems. Smaller theropods probably adapted to life with tyrannosaurs by hunting in groups, feeding rapidly, and avoiding encounters with their larger cousins whenever possible. This would have favored improved hunting skills and associated adaptations such as agility, speed, intelligence, and increased sensory awareness. With additional discoveries of more complete specimens of theropods, it will be fascinating to compare more fully the sensory, feeding, and locomotor capabilities of sympatric theropods. Much remains to be discovered.

\section{Acknowledgments}

We gratefully acknowledge two thoughtful anonymous reviewers as well as S. Wing, W. DiMichele, J. Downs, and G. Erickson for their helpful and insightful comments. We also thank D. Simberloff for assistance with the Barton-David statistics.

\section{Literature Cited}

Anderson, J. F., A. Hall-Martin, and D. A. Russell. 1985. Longbone circumference and weight in mammals, birds and dinosaurs. Journal of Zoology 207:53-61.

Auffenberg, W. 1981. The behavioral ecology of the Komodo monitor. University Presses of Florida, Gainesville. 
Barsbold, R. 1974. Saurornithoididae, a new family of small theropod dinosaurs from central Asia and North America. Acta Palaeontologia Polonica 30:5-22.

Barton, D. E., and F. N. David. 1956. Some notes on ordered random intervals. Journal of the Royal Statistical Society B 18:7994.

Biknevicius, A. R., and C. B. Ruff. 1992. The structure of the mandibular corpus and its relationship to feeding behaviours in extant carnivorans. Journal of Zoology 228:479-507.

Biknevicius, A., and B. Van Valkenburgh. 1996. Design for killing: craniodental adaptations of predators. Pp. 393-428 in J. L. Gittleman, ed. Carnivore behavior, ecology, and evolution, Vol. II. Cornell University Press, Ithaca, N.Y.

Britt, B. 1991. Theropods of Dry Mesa Quarry (Morrison Formation, Late Jurassic, Colorado) with emphasis on the osteology of Torvosaurus tanneri. Brigham Young University Geological Studies 37:1-72.

Carbone, C., G. M. Mace, S. C. Roberts, and D. W. Macdonald. 1999. Energetic constraints on the diet of terrestrial carnivores. Nature 402:286-288.

Carpenter, K. 1992. Tyrannosaurids (Dinosauria) of Asia and North America. Pp. 250-268 in N. J. Mateer and P.-J. Chen, eds. Aspects of nonmarine Cretaceous geology. China Ocean Press, Beijing.

Carr, T. D. 1999. Craniofacial ontogeny in tyrannosauridae (Dinosauria, Coelurosauria). Journal of Vertebrate Paleontology 19:497-520.

Carrano, M. T. 1999. What, if anything, is a cursor? Journal of Zoology 247:29-42.

Chin, K., T. T. Totaryl, G. M. Erickson, and L. C. Calk. 1998. A king-sized theropod coprolite. Nature 393:680-682.

Chure, D. J. 1994. Koparion douglassi, a new dinosaur from the Morrison Formation (Upper Jurassic) of Dinosaur National Monument; the oldest troodontid (Theropoda: Maniraptora). Brigham Young University Geology Studies 40:11-15.

1995. A reassessment of the gigantic theropod Saurophagus maximus from the Morrison Formation (Upper Jurassic) of Oklahoma, USA. Pp. 103-106 in A. Sun and Y. Wang, eds. Short papers, Sixth symposium on Mesozoic terrestrial ecosystems and biota, 1995. China Ocean Press, Beijing.

Colbert, E. H. 1962. The weights of dinosaurs. American Museum Novitates 2076:1-16.

Colbert, E. H., and D. A. Russell. 1969. The small Cretaceous dinosaur Dromaeosaurus. American Museum Novitates 1900: $1-20$.

Currie, P. J. 1990. Elmisauridae. Pp. 245-248 in D. B. Weishampel, P. Dodson, and H. Osmolska, eds. The Dinosauria. University of California Press, Berkeley.

Currie, P. J., and A. R. Jacobsen. 1995. An azhdarchid pterosaur eaten by a velociraptorine theropod. Canadian Journal of Earth Sciences 32:922-925.

Currie, P. J., and D. A. Russell. 1988. Osteology and relationships of Chirostenotes pergracilis (Saurischia, Theropoda) from the Judith River (Oldman) Formation of Alberta, Canada. Canadian Journal of Earth Sciences 25:972-986.

Dayan, T., and D. Simberloff. 1994. Character displacement, sexual dimorphism, and morphological variation among British and Irish mustelids. Ecology 75:1063-1073.

Dayan, T., E. Tchernov, Y. Yom-Tov, and D. Simberloff. 1989a. Ecological character displacement in Saharo-Arabian Vulpes: outfoxing Bergmann's rule. Oikos 55:263-272.

Dayan, T., D. Simberloff, E. Tchernov, and Y. Yom-Tov. 1989b. Inter- and intraspecific character displacement in mustelids. Ecology 70:1526-1539.

___ 1990. Feline canines: community-wide character displacement among the small cats of Israel. American Naturalist 136:39-60.

1992. Canine carnassials: character displacement in the wolves, jackals and foxes of Israel. Biological Journal of the Linnean Society 45:315-331.

Dodson, P. 1971. Sedimentology and taphonomy of the Oldman Formation (Campanian), Dinosaur Provincial Park, Alberta (Canada). Palaeogeography, Palaeoclimatology, Palaeoecology 10:21-74.

1983. A faunal review of the Judith River (Oldman) formation, Dinosaur Provincial Park, Alberta. Mosasaur 1:89118.

Eaton, R. L. 1979. Interference competition among carnivores: a model for the evolution of social behavior. Carnivore 2:9-16.

Eberth, D. A., R. G. Thomas, and A. Deino. 1992. Preliminary KAr dates from bentonites in the Judith River and Bearpaw Formations (Upper Cretaceous) of Dinosaur Provincial park, southern Alberta, Canada. Pp. 296-304 in N. J. Mateer and P.-J. Chen, eds. Aspects of nonmarine Cretaceous geology. China Ocean Press, Beijing.

Emerson, S. B., H. W. Greene, and E. L. Charnov. 1994. Allometric aspects of predator-prey interactions. Pp. 123-139 in P. C. Wainwright and S. M. Reilly, eds. Ecological morphology: integrative organismal biology. University of Chicago Press, Chicago.

Erickson, G. M., and K. H. Olson. 1996. Bite marks attributable to Tyrannosaurus rex: preliminary description and implications. Journal of Vertebrate Paleontology 16:175-178.

Erickson, G. M., S. D. Van Kirk, J. Su, M. E. Levenston, W. E. Caler, and D. R. Carter. 1996. Bite-force estimation for Tyrannosaurus rex from tooth-marked bones. Nature 382:706-708.

Ewer, R. F. 1973. The carnivores. Weidenfeld and Nicolson, London.

Fanshawe, J. H., and C. D. Fitzgibbon. 1993. Factors influencing the hunting success of an African Wild Dog pack. Animal Behaviour 45:479-490.

Farlow, J. O. 1993. On the rareness of big, fierce animals: speculations about the body sizes, population densities, and geographic ranges of predatory mammals and large carnivorous dinosaurs. American Journal of Science 293A:167-199.

Farlow, J. O., D. L. Brinkman, W. L. Abler, and P. J. Currie. 1991. Size, shape and serration density of theropod dinosaur lateral teeth. Modern Geology 16:161-198.

Farlow, J. O., M. B. Smith, and J. R. Robinson. 1995. Body mass, bone "strength indicator" and cursorial potential of Tyrannosaurus rex. Journal of Vertebrate Paleontology 15:713-725.

Fiorillo, A. R. 1991. Prey bone utilization by predatory dinosaurs. Palaeogeography, Palaeoclimatology, Palaeoecology 88:157-166

Foster, J. R., and D. J. Chure. 1998. Patterns of theropod diversity and distribution in the Late Jurassic Morrison Formation, Western USA. Pp. 30-31 in Abstracts and Programs for the Fifth International Symposium on the Jurassic System, International Union of Geological Sciences Subcommission on Jurassic Stratigraphy. Vancouver, Canada.

Gilmore, C. W. 1920. Osteology of the carnivorous Dinosauria in the United States National Museum, with special reference to the genera Antrodemus (Allosaurus) and Ceratosaurus. Bulletin of the United States National Museum 110:1-154.

- 1924. A new coelurid dinosaur from the Belly River Cretaceous of Alberta. Bulletin of the Canadian Department of Mines, Geological Survey 38:1-12.

__ 1946. A new carnivorous dinosaur from the Lance Formation of Montana. Smithsonian Miscellaneous Collections 106:1-19.

Gittleman, J. L., and P. H. Harvey. 1982. Carnivore home-range size, metabolic needs, and ecology. Behavioral Ecology and Sociobiology 10:57-63.

Glut, D. F. 1997. Dinosaurs, the encyclopedia. McFarland, Jefferson, N.C.

Gradzinski, R., and T. Jerzykiewicz. 1972. Additional geograph- 
ical and geological data from the Polish-Mongolian palaeontological expeditions. Acta Palaeontologia Polonica 27:17-30.

Gradzinski, R., J. Kazmierczak, and J. Lefeld. 1968. Geographical and geological data from the Polish-Mongolian palaeontological expeditions. Acta Palaeontologia Polonica 19:33-82.

Haynes, G. 1982. Utilization and skeletal disturbances of North American prey carcasses. Arctic 35:266-281.

Hutchinson, G. E., and R. H. MacArthur. 1959. A theoretical ecological model of size distributions among species of animals. American Naturalist 93:117-125.

Hutchinson, J. R., and M. Garcia. 2002. Tyrannosaurus was not a fast runner. Nature 415:1018-1021.

Jaksic, F., H. W. Greene, and J. L. Yanez. 1981. The guild structure of a community of predatory vertebrates in central Chile. Oecologia 49:21-28.

Kiltie, R. F. 1988. Interspecific size regularities in tropical felid assemblages. Oecologia 76:97-105.

Kobayashi, Y., J.-C. Lu, Z.-M. Dong, R. Barsbold, Y. Azuma, and Y. Tomida. 1999. Herbivorous diet in an ornithomimid dinosaurs. Nature 402:480-481.

Kruuk, H. 1972. The spotted hyena. University of Chicago Press, Chicago.

Losos, J. B., and H. W. Greene. 1988. Ecological and evolutionary implications of diet in monitor lizards. Biological Journal of the Linnean Society 35:379-407.

Madsen, J. H., Jr., and S. P. Welles. 2000. Ceratosaurus (Dinosauria, Theropoda) a revised osteology. Miscellaneous Publication, Utah Geological Survey, 00-2:1-80.

Maleev, E. A. 1974. Giganskei karnozavrii semeistva Tyrannosauridae. Sovmestnaia Sovetsko-Mongoliskaia Paleontologicheskaia Yekspeditsiia, Trudi 1:132-191.

Molnar, R. E. 2000. Mechanical factors in the design of the skull of Tyrannosaurus rex (Osborn, 1905). Gaia 15:193-218.

Muckenhirn, N. A., and J. F. Eisenberg. 1973. Home ranges and predation of the Ceylon leopard. Pp. 142-175 in R. L. Eaton, ed. The world's cats, Vol. 1. Winston Wildlife Safari, Winston, Ore.

Osborn, H. F. 1916. Skeletal adaptations of Ornitholestes, Struthiomimus, Tyrannosaurus. Bulletin of the American Museum of Natural History 35:733-771.

Osmolska, H. 1996. An unusual theropod dinosaur from the Late Cretaceous Nemegt Formation of Mongolia. Acta Palaeontologica Polonica 41:1-38.

Ostrom, P. H., S. A. Macko, M. H. Engel, and D. A. Russell. 1993. Assessment of trophic structure of Cretaceous communities based on stable nitrogen isotope analysis. Geology 21:491494.

Palomares, F., and T. M. Caro. 1999. Interspecific killing among mammalian carnivores. American Naturalist 153:492-508.

Paul, G. S. 1988. Predatory dinosaurs of the world. Simon and Schuster, New York.

Peczkis, J. 1994. Implications of body-mass estimates for dinosaurs. Journal of Vertebrate Paleontology 14:520-533.

Pianka, E. R. 1994. Comparative ecology of Varanus in the Great Australian Desert. Australian Journal of Ecology 19:395-408.

Polis, G. A., and R. D. Holt. 1992. Intraguild predation: the dynamics of complex trophic interactions. Trends in Ecology and Evolution 7:151-154

Rayfield, E. J., D. B. Norman, C. C. Horner, J. R. Horner, P. M. Smith, J. J. Thomason, and P. Upchurch. 2001. Cranial design and function in a large theropod dinosaur. Nature 409:10331037.

Root, R. B. 1967. The niche exploitation pattern of the blue-gray gnatcatcher. Ecological Monographs 37:317-350.

Russell, D. A. 1969. A new specimen of Stenonychosaurus from the Oldman Formation (Cretaceous) of Alberta. Canadian Journal of Earth Sciences 6:595-612.

1970. Tyrannosaurs from the Late Cretaceous of western Canada. Publications in Palaeontology, National Museum of Natural Sciences (Ottawa) 1:1-34.

Seidensticker, J. 1976. On the ecological separation between tigers and leopards. Biotropica 8:225-234.

Seidensticker, J., M. E. Sunquist, and C. McDougal. 1990. Leopards living at the edge of Royal Chitawan National Park, Nepal. Pp. 415-423 in J. C. Daniel and J. S. Serrao, eds. Conservation in developing countries: problems and prospects. Bombay Natural History Society, Bombay.

Simberloff, D., and W. Boecklen. 1981. Santa Rosalia reconsidered: size ratios and competition. Evolution 35:1206-1228.

Simberloff, D., and T. Dayan. 1991. The guild concept and the structure of ecological communities. Annual Review of Ecology and Systematics 22:115-143.

Stanley, S. M. 1979. Macroevolution: pattern and process. W. H. Freeman, San Francisco.

Tiffney, B. H. 1984. Seed size, dispersal syndromes, and the rise of the angiosperms: evidence and hypothesis. Annals of the Missouri Botanical Garden 71:551-576.

Turner, C. E., and F. Peterson. 1999. Biostratigraphy of dinosaurs in the upper Jurassic Morrison Formation of the western interior, U.S.A. Pp. 77-114 in D. D. Gillette, ed. Vertebrate paleontology in Utah. Utah Geological Survey Miscellaneous Publication 99-1.

Van Valen, L. 1973. Body size and numbers of plants and animals. Evolution 27:27-35.

Van Valkenburgh, B. 1985. Locomotor diversity within past and present guilds of large predatory mammals. Paleobiology 11: 406-428.

1988. Trophic diversity within past and present guilds of large predatory mammals. Paleobiology 14:156-173.

1989. Carnivore dental adaptations and diet: a study of trophic diversity within guilds. Pp. 410-436 in J. L. Gittleman, ed. Carnivore behavior, ecology, and evolution, Vol. I. Cornell University Press, Ithaca, N.Y.

- 1991. Iterative evolution of hypercarnivory in canids (Mammalia: Canidae): evolutionary interactions among sympatric predators. Paleobiology 17:340-362.

1994. Extinction and replacement among predatory mammals in the North American Late Eocene-Oligocene: tracking a guild over twelve million years. Historical Biology $8: 1-22$

- 2001. The dog-eat-dog world of carnivores: a review of past and present carnivore community dynamics. Pp. 101-121 in C. Stanford and H. T. Bunn, eds. Meat-eating and human evolution. Oxford University Press, Oxford.

Van Valkenburgh, B., and F. Hertel. 1998. The decline of North American predators during the Late Pleistocene. In J. J. Saunders, B. W. Styles, and G. F. Baryshnikov, eds. Quaternary paleozoology in the Northern Hemisphere. Illinois State Museum Scientific Papers 27:357-374.

Van Valkenburgh, B., and K. Koepfli. 1993. Cranial and dental adaptations for predation in canids. In N. Dunstone and M. L. Gorman, eds. Mammals as predators. Symposia of the Zoological Society of London 65:15-37. Oxford University Press, Oxford.

Van Valkenburgh, B., and C. B. Ruff. 1987. Canine tooth strength and killing behaviour in large carnivores. Journal of Zoology 212:379-398

Weishampel, D. B. 1990. Dinosaurian distribution. Pp. 63-139 in D. B. Weishampel, P. Dodson and H. Osmolska, eds. The Dinosauria. University of California Press, Berkeley.

Wing, S. L., and B. H. Tiffney. 1987. The reciprocal interaction of angiosperm evolution and tetrapod herbivory. Review of Palaeobotany and Palynology 50:179-210. 